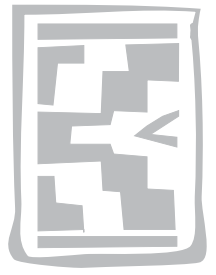

\title{
Occurrence of multiple drug resistance in Trypanosoma brucei rhodesiense isolated from sleeping sickness patients
}

\author{
J.M. KAGIRA ${ }^{1 *}$ and N. MAINA ${ }^{2}$
}

\begin{abstract}
KAGIRA, J.M. \& MAINA, N. 2007. Occurrence of multiple drug resistance in Trypanosoma brucei rhodesiense isolated from sleeping sickness patients. Onderstepoort Journal of Veterinary Research, 74:17-22

The occurrence of cross-resistance among melarsoprol-resistant Trypanosoma brucei rhodesiense isolates was investigated in this study. The isolates, T. b. rhodesiense KETRI 237, 2538, 1992, 2709, 2694 and 3530, had been obtained from sleeping sickness patients in Kenya and Uganda between 1960 and 1985. Five groups consisting of six mice each were inoculated intraperitoneally with $10^{5}$ parasites of each isolate, and $24 \mathrm{~h}$ later treated with either melarsoprol, homidium chloride, diminazene aceturate or isometamidium chloride. The control group comprised infected but untreated mice. The mice were monitored for cure for a period of 60 days post-treatment. The mean prepatent period in the control mice was 5 days while the mean survival period was 22 days. Five of the stabilates, KETRI 237, 2538, 2709, 2694, and 3530, were confirmed to be melarsoprol resistant. Cross-resistance was observed, with the majority of the isolates being resistant to homidium chloride $(5 / 6)$ and diminazene aceturate (5/6), but all were sensitive to isometamidium chloride (6/6). However $T$. $b$. rhodesiense KETRI 1992, which was previously considered as melarsoprol resistant, was sensitive to all the drugs tested. In conclusion, our study has revealed the existence of cross-resistance among the melarsoprol resistant isolates which could only be cured by isometamidium.
\end{abstract}

Keywords: Cross-resistance, Kenya, melarsoprol, trypanocidals, Trypanosoma brucei rhodesiense, Uganda

\section{INTRODUCTION}

Chemotherapy remains the principal control method of both animal and human trypanosomosis. The emergence of drug-resistant trypanosome strains is considered a serious problem in trypanosomosis control however, particularly for the resource-poor, at-risk populations and farmers in Africa. So far, re-

* Author to whom correspondence is to be directed. E-mail: jkagira@yahoo.com

1 Kenya Agricultural Research Institute-Trypanosomiasis Research Centre (KARI-TRC), P.O. Box 362, Kikuyu, Kenya

2 Department of Biochemistry, Jomo Kenyatta University of Agriculture and Technology, P.O. Box 62000 Nairobi, Kenya

Accepted for publication 15 September 2006-Editor sistance to one or more of the trypanocides used in livestock has been reported in at least 13 Africa countries (Ndung'u, Murilla, Mdachi, Mbwambo, Sinyangwe, Machila, Delespaux, Geerts, Brandt, Peregrine, McDermott, Holmes \& Eisler 1999; Anene, Onah \& Nawa 2001). The main factors associated with the emergence of resistance include the prolonged and improper use of the trypanocidal drugs in both humans and livestock.

Human sleeping sickness is caused by Trypanosoma brucei rhodesiense and $T$. brucei gambiense, both of which also infect some domestic and wild animals. Results of studies on the role of the livestock reservoir in the epidemiology of $T$. $b$. rhodesiense sleeping sickness have indicated that an aggressive chemotherapy policy should be pursued in livestock 
in endemic areas (Angus 1996; Fervre, Coleman, Odiit, Magona, Welburn \& Woolhouse 2001). This is due to an incidence of up to $20 \%$ of $T$. b. rhodesiense in cattle in endemic areas (Hide, Angus, Holmes, Maudlin \& Welburn 1998). The widespread use of trypanocides, especially diminazene aceturate (diminazene) and isometamidium chloride (isometamidium), acts as a selection pressure for the development of resistant trypanosomes (Angus 1996). It is hypothesized that trypanosomes infective for humans can be selected for drug resistance during treatment of livestock and that they might subsequently be introduced to humans by tsetse flies. Indeed, a study carried out during the 19881990 sleeping sickness epidemic in the Busoga district in Uganda showed that the disease is up to five times more likely to be transmitted by the cattle-flyhuman transmission cycle than the human-fly-human cycle (Hide, Tait, Maudlin \& Welburn 1996).

Reduced sensitivity of $T . b$. rhodesiense isolates to trypanocides used in cattle has been reported in Kenya and Uganda (Van Hoeve \& Grainge 1965; Matovu, Iten, Enyaru, Schmid, Lubega, Brun \& Kaminsky 1997). Mice infected with $T$. $b$. rhodesiense isolated from a human patient were refractory to diminazene administered at the normal dosage levels (Matovu et al. 1997). In another study, a T. $b$. rhodesiense stock isolated from cattle was found to be clearly resistant to diminazene and isometamidium (Enyaru, Matovu, Lubega \& Kaminsky 1998). In the latter study, diminazene at $14 \mathrm{mg} / \mathrm{kg}$ was not sufficient to cure all mice, while $33 \%$ of mice treated with isometamidium at $2 \mathrm{mg} / \mathrm{kg}$ were not cured. These studies showed that the control of sleeping sickness by treatment of the animal reservoir could face serious problems since the drug-resistant parasites would most likely not be eliminated by diminazene and isometamidium administered at the recommended dosage levels (Matovu et al. 1997; WHO 2001).

A reduced virulence of resistant isolates has been observed in many pathogenic organisms. In trypanosomes, the existence of such a scenario has been inconsistent, although most studies have shown that the resistant strains are less virulent than the parental clone (Kaminsky \& Zweygarth 1989; Egbe-Nwiyi, Igbokwe \& Onyeyili 2005). Due to the presence of mixed infections of trypanosome strains with different drug sensitivities in a single host, it is postulated that competition between the strains will arise (Mutugi 1993). The sensitive trypanosomes will grow faster and develop an infection earlier than the slower growing resistant strains, a situation that may result in selecting out of the latter. Indeed, it has been shown that although suramin resistance in T. evansi is highly stable, its spread is quite limited (Mutugi 1993). It has been suggested that lack of spread of suramin-resistant $T$. evansi is occasioned by poor survival of the resistant isolates as compared to the sensitive and more pathogenic ones (Mutugi, Boid \& Luckins 1996). The possible existence of such a scenario in $T$. b. rhodesiense isolates has not yet been investigated to date.

The objective of this study was to determine the pathogenicity and possible occurrence of cross-resistance among melarsoprol-resistant $T$. b. rhodesiensecryopreserved at the Trypanosomosis Research Centre (TRC) in Kenya. Standardized tests and methods of interpretation of results (Eisler, Brandt, Bauer, Clausen, Delespaux, Holmes, llemobade, Machila, Mbwambo, McDermott, Mehlitz, Murilla, Ndung'u, Peregrine, Sidibe, Sinyangwe \& Geerts 2001) were used in this study.

\section{MATERIALS AND METHODS}

\section{Ethical review}

All the procedures used in this study were reviewed and approved by the Institutional Animal Care and Use Committee (IACUC) of the TRC in Nairobi, Kenya.

\section{Trypanosomes}

Six $T . b$. rhodesiense isolates, which had been determined to be resistant to melarsoprol, were used. The isolates included $T . b$. rhodesiense numbers KETRI 237, 2538, 1992, 2709, 2694 and 3530 (hereafter referred by their specific numbers). These isolates were characterized by other workers and found to be melarsoprol-resistant (Baachi, Nathan, Livingston, Valladares, McCann, Bitonti, Sjoersma, Saric, Sayer, Njogu \& Clarkson 1990; Brun, Schumacher, Schomidiumid, Kunz \& Burri 2001). In this study, the trypanosomes were multiplied in gamma-irradiated Swiss white mice. At the rising wave of parasitaemia, the mice were euthanased by placing them in an atmosphere of carbon dioxide and trypanosomes harvested through cardiac puncture.

\section{Mice}

Swiss white mice weighing 20-30 g were obtained from the laboratory-animal breeding colony at the TRC. The mice were kept in cages where they were fed on commercial pellets and water ad libitum. 


\section{Drugs}

Isometamidium chloride (Samorin $\AA$, Merial, France), diminazene aceturate (Berenil $\AA$, Hoechst, Ireland) and homidium chloride (Novidium $\AA$, May \& Baker, UK) were prepared by dissolving in sterile distilled water. Melarsoprol (Arsobal ${ }^{\circ}$, Aventis) was prepared using propylene glycol as the diluent.

\section{Experimental design}

\section{Pathogenicity}

Groups of six mice were inoculated intraperitoneally with $10^{5}$ parasites of the isolates studied. The mice, which also served as the control groups for the sensitivity studies (see below), were monitored for the pre-patent period, parasitaemia pattern and survival period. The parasitaemia levels were estimated daily using the rapid matching method (Herbert \& Lumsden 1976). Mice in extremis were euthanased and necropsied.

\section{Sensitivity study}

Groups of six mice were inoculated intraperitoneally with $10^{5}$ parasites of the isolates listed above. Twenty-four hours after inoculation, trypanocidal drugs were administered, also intraperitoneally. Isometamidium, diminazene, homidium and melarso- prol were given at dosage rates of $1.0 \mathrm{mg}, 20 \mathrm{mg}$, $1.0 \mathrm{mg}$ and $10 \mathrm{mg} / \mathrm{kg}$ body mass, respectively. After treatment, the parasitaemia was monitored daily during the first week, three times a week during the second week and twice a week thereafter in wet smears of tail blood. The treated groups were monitored until relapse occurred or until 60 days posttreatment, when the mice were euthanased.

\section{Interpretation}

The results of the study were interpreted as described by Eisler et al. (2001). A trypanosome isolate was considered as drug sensitive if at least five out of six treated mice were cured. If fewer than five mice were cured, the isolate was considered resistant.

\section{RESULTS}

\section{Pathogenicity study (Table 1)}

The mean pre-patent period in the infected nontreated mice was 5 days (range 4-6 days). The parasitaemia pattern varied between the isolates, with most isolates producing several peaks of parasitaemia before killing the mice. The mean survival period was 22 days (range 17-29 days). Mice infected with KETRI 237 had the shortest survival period

TABLE 1 Pathogenicity of the different T.b. rhodesiense isolates

\begin{tabular}{|l|l|l|}
\hline Isolate number & Mean prepatent period days (range) & Mean survival period in days (range) \\
\hline KETRI 2538 & $6(4-6)$ & $18(16-20)$ \\
KETRI 1992 & $6(4-12$ & $24(22-31)$ \\
KETRI 237 & $5(4-7)$ & $17(16-18)$ \\
KETRI 2694 & $4(4-5)$ & $29(24-35)$ \\
KETRI 3530 & $4(3-6)$ & $22(17-29)$ \\
KETRI 2709 & $4(3-5)$ & $22(12-32)$ \\
\hline
\end{tabular}

TABLE 2 Sensitivity of T.b. rhodesiense isolates to different trypanocidal drugs

\begin{tabular}{|l|l|l|l|l|l|l|l|l|}
\hline \multirow{2}{*}{ Isolate number } & \multicolumn{4}{l|}{ Number of mice cured* } & \multicolumn{3}{l|}{ Time to relapse (days) $^{*}$} \\
\cline { 2 - 9 } & ISMM & HM & DA & Mel B & ISMM & HM & DM & Mel B \\
\hline KETRI 2538 & $5 / 6$ & $0 / 6$ & $2 / 6$ & $0 / 6$ & 53 & 8 & 13 & 7 \\
KETRI 1992 & $6 / 6$ & $6 / 6$ & $6 / 6$ & $6 / 6$ & 0 & 0 & 0 & 0 \\
KETRI 237 & $6 / 6$ & $0 / 6$ & $0 / 6$ & $0 / 6$ & 0 & 9 & 12 & 4 \\
KETRI 2694 & $6 / 6$ & $4 / 6$ & $4 / 6$ & $0 / 6$ & 0 & 29 & 32 & 4 \\
KETRI 3530 & $6 / 6$ & $1 / 6$ & $4 / 6$ & $5 / 6$ & 0 & 11 & 22 & 15 \\
KETRI 2709 & $6 / 6$ & $0 / 6$ & $4 / 6$ & $1 / 6$ & 0 & 9 & 11 & 7 \\
\hline
\end{tabular}

$\begin{array}{ll}{ }^{*} \text { ISMM } & =\text { Isometamidium chloride } \\ \text { DA } & =\text { Diminazene aceturate } \\ \text { HM } & =\text { Homidium chloride } \\ \text { Mel B } & =\text { Melarsoprol } \\ \text { Resistant isolates } & =0 / 6-4 / 6 \\ \text { Sensitive isolates } & =5 / 6-6 / 6\end{array}$


while those infected with KETRI 2694 had the longest. The most noticeable lesions at post mortem examination of all the mice that died were enlarged spleens and congestion of most organs.

\section{Sensitivity study (Table 2)}

Five of the isolates investigated were confirmed to be melarsoprol-resistant. Cross-resistance was observed in these isolates, with the majority being resistant to homidium and diminazene, and only sensitive to isometamidium. However, different levels of sensitivities to specific drugs were observed among the isolates. KETRI 2694, 3530, and 2694 were found to have a higher sensitivity to diminazene when compared to that of other isolates. KETRI 2694 was also relatively sensitive to homidium when compared to that of the other isolates.

All mice infected with KETRI 1992 were cured with all the drugs used. This is despite the fact that the parasite was previously recorded as being resistant to melarsoprol. The time taken before a relapse occurred varied between isolates and the drugs used, with the shortest time being observed mainly in melarsoprol-treated groups. For the homidium-treated groups, KETRI 2538 had the least number of days to relapse while KETRI 2694 had the most. However, for diminazene-treated groups, KETRI 2709 had the least number of days to relapse. For melarsoprol, KETRI 237 and 2694 had the least number of days to relapse while KETRI 3530 had the most.

\section{DISCUSSION}

Previous studies have shown that T. b. rhodesiense infections in livestock can be effectively cured (Angus 1996; Matovu et al. 1997). Thus, mass chemotherapy of animals acting as reservoirs of $T$. b. rhodesiense has been advocated as an effective strategy for control of the spread of sleeping sickness (Fevre et al. 2001). This approach can be hindered by the emergence of resistant trypanosomes, which can also be spread from humans to cattle and vice versa (Matovu et al. 1997). It is also evident that resistance of $T . b$. brucei to diminazene is a significant problem in trypanosomosis-endemic areas (Ndung'u et al. 1999; Anene et al. 2001; Anene, Ezeokonkwo, Mmesirionye, Tettey, Brock, Barrett \& De Koning 2006).

From the stocks analysed in this study, melarsoprolresistant isolates were also shown to be cross-resistant to both diminazene and homidium. The latter are curative livestock trypanocides and are used at a dosage lower than the one used in this study. The cross-resistance between arsenicals and diamidines has been widely investigated and is partially associated with loss of adenosine P2 transporters in the resistant trypanosomes (Carter \& Fairlamb 1993; Barrett \& Fairlamb 1999; De Koning, Anderson, Stewart, Burchmore, Wallace \& Barrett 2004). Since diminazene is the most commonly used drug in the field, the occurrence of resistance in $5 / 6$ of the tested isolates is particularly important in controlling the spread of resistant isolates. Fortunately, only a few cases of melarsoprol resistance have been reported in T. b. rhodesiense patients in recent years (Matovu et al. 1997; Kibona, Matemba, Kaboya \& Lubega 2006). The lack of spread of these isolates could be due several factors, which include: low transmissibility of resistant isolates, low transmission capacity from humans to livestock and reduction in the incidence rates of the Rhodesian type of sleeping sickness (Brun et al. 2001). On the contrary, the emergence of numerous cases of patients with $T . b$. gambiense resistant to melarsoprol is of great concern (Brun et al. 2001; Matovu, Seebeck, Enyaru \& Kaminsky 2001). In endemic countries, this has necessitated the change of the treatment regimen for late-stage disease from melarsoprol to eflornithine (Brun et al. 2001; Legros, Ollivier, Gastellu-Etchegorry, Paquet, Burri, Jannin \& Büscher 2002).

The large proportion of homidium-resistant isolates in the current study was unexpected, especially because a related phenanthridinium compound, isometamidium, cured all the infected mice. The biochemical mechanism of homidium resistance is not clear, although there is evidence that homidium-resistant $T$. bruceiclones accumulate smaller amounts of the drug than their sensitive counterparts (Frommel \& Balber 1987). Homidium was extensively used in the 1960s and 1970s when most of the parasites used in this study were isolated. However, its usefulness was curtailed by widespread emergence of resistance (Scott \& Pegram 1974). Thus, one cannot rule out the possible spread of the homidiumresistant isolates from livestock to humans during the two decades. It can be hypothesized that this phenomenon could have led to the subsequent emergence of resistance to both melarsoprol and diminazene, as observed in this study. The existence in cattle of $T$. b. rhodesiense resistant to homidium and other drugs used for routine treatment was also reported in Kenya in 1960s (Van Hoeve \& Grainge 1965). Cross-resistance between homidium and diminazene was reported in cattle (Schonfield, Rottcher \& Moloo 1987; Codja, Mulatu, Majiwa, Leak, Rowlands, Authie, D'leteren \& Peregrine 1993). 
Isometamidium is as regarded a hybrid molecule which contains homidium and an additional moiety of $m$-amidinophenyl-azo-amine that is part of the diminazene molecule (Wragg, Washbourn, Brown \& Hill 1958). These combined properties of diminazene and homidium could be responsible for curing $100 \%$ of the isolates used in this study. The prophylactic use of this drug in the field could thus be an effective tool in controlling the spread of melarsoprol-resistant trypanosomes should they emerge. Cross-resistance between isometamidium and diminazene rarely occurs in the field and, as such, they are used as a sanative combination to curtail the development of resistance to either drug (Whitesand 1960).

The pathogenicity of trypanosomes used in these studies was not significantly different from that of the corresponding sensitive stabilates. In most cases, the prepatent period ranges between 3-6 days (Kagira, unpublished data 2005). However, there was a wide range in the survival period of mice infected with the different isolates. The relationship between the virulence of the trypanosomes and sensitivity to different drugs could not be accurately assessed, as we did not have the original stabilates before resistance emerged. However, mice infected with more sensitive isolates (KETRI 1992 and 2694) survived longer when compared to those that were highly resistant. Other studies have documented reduced virulence amongst resistant $T$. brucei and $T$. evansistrains (Mutugi 1993; Egbe-Nwiyi et al. 2005). Thus, it is hypothesized that sensitive trypanosomes will grow faster and hinder the spread of the resistant ones (Mutugi et al. 1993).

In conclusion, our study has revealed the existence of multiple resistance among the melarsoprol-resistant isolates. The results suggest that isometamidium can be used to curtail the spread of such resistance. However, the results should also be considered with caution since drug pharmacokinetics and immune response differ between animal species, and responses in mice might not be able to be directly extrapolated to the situation in cattle.

\section{ACKNOWLEDGEMENTS}

The study was funded by Government of Kenya. We thank Dr John Thuita of the Primate Division, Trypanosomiasis Research Centre, who participated in the development of the protocols. We are also grateful for the technical assistance provided by Messrs Ben Kinyanjui, Tom Adino, Stephen Mwangi and John Oidho of the Primate Division, TRC.

\section{REFERENCES}

ANENE, B.M., EZEOKONKWO, R.C., MMESIRIONYE, T.I., TETTEY, J.N., BROCK, J.M., BARRETT, M.P. \& DE KONING, H. P. 2006. A diminazene-resistant strain of Trypanosoma brucei brucei isolated from a dog is cross-resistant to pentamidine in experimentally infected albino rats. Parasitology, 132:127133.

ANENE, B.M., ONAH, D.N. \& NAWA, Y. 2001. Drug resistance in pathogenic African trypanosomes: what hopes for the future? Veterinary Parasitology, 96:83-100.

ANGUS, S.D. 1996. The epidemiology of trypanosomosis in village livestock in an endemic sleeping sickness area of western Kenya. Ph.D. thesis, University of Glasgow.

BAACHI, C.J., NATHAN, H.C., LIVINGSTON, T., VALLADIMINAZENERES, G., MCCANN, P.P., BITONTI, A.J., SJOERSMA, A., SARIC, M., SAYER, P., NJOGU, A.R. \& CLARKSON, A. B. 1990. Differential sensitivity of DL- $\alpha$-difluoromethylornithine in clinical isolates of Trypanosoma brucei rhodesiense. Antimicrobial Agents and Chemotherapy, 34:1183-1188.

BARRETT, M.P. \& FAIRLAMB, A.H. 1999. The biochemical basis of arsenical-diamidine cross-resistance in African trypanosomes. Parasitology Today, 15:136-140.

BRUN, R., SCHUMACHER, R., SCHMID, C., KUNZ, C. \& BURRI, C. 2001. The phenomenon of treatment failures in human African trypanosomosis. Tropical Medicine and International Health, 6:906-914.

CARTER, N.S. \& FAIRLAMB, A.H. 1993. Arsenical resistant trypanosomes lack an unusual adenosine transporter. Nature, 361:173-176.

CODJA, V., MULATU, W., MAJIWA, P.A.O., LEAK, S.G.A., ROWLANDS, G.J., AUTHIE, E., D'IETEREN, G.D.M. \& PEREGRINE, A.S. 1993. Epidemiology of trypanosomosis in Ghibe valley, south-western Ethiopia. 3. Occurrence of populations of Trypanosoma congolense resistant to diminazene, isometamidium and homidium. Acta Tropica, 53:151-163.

DE KONING, H.P., ANDERSON, L.F., STEWART, M., BURCHMORE, R.J., WALLACE, L.J. \& BARRETT, M.P. 2004. The trypanocide diminazene aceturate is accumulated predominantly through the TbAT1 purine transporter: additional insights on diamidine resistance in African trypanosomes. Antimicrobial Agents and Chemotherapy 48:1515-1519.

EGBE-NWIYI, T.N., IGBOKWE, I.O. \& ONYEYILI, P.A. 2005. Diminazene aceturate resistance on the virulence of Trypanosoma brucei for rats. Comparative Pathology, 133:286-288.

EISLER, M.C., BRANDT, J., BAUER, B., CLAUSEN, P.-H., DELESPAUX, V., HOLMES, P.H., ILEMOBADE, A., MACHILA, N., MBWAMBO, H., McDERMOTT, J., MEHLITZ, D., MURILLA, G., NDUNG'U, J.M., PEREGRINE, A.S., SIDIBE, I., SINYANGWE, L. \& GEERTS, S. 2001. Standardised tests in mice and cattle for detection of drug resistance in tsetsetransmitted trypanosomes of African domestic cattle. Veterinary Parasitology, 97:171-182.

ENYARU, J.C., MATOVU, E., LUBEGA, G.W. \& KAMINSKY, R. 1998. Response of a Trypanosoma brucei rhodesiense stock with reduced drug susceptibility in vitro to treatment in mice and cattle. Acta Tropica, 69:261-269.

FERVRE, E.M., COLEMAN, P.G., ODIIT, M., MAGONA, J.W., WELBURN, S.C. \& WOOLHOUSE, M.E.J.W. 2001. The origins of a new Trypanosoma brucei rhodesiense outbreak in eastern Uganda. Lancet, 358:625-628.

FROMMEL, T.O. \& BALBER, A.E. 1987. Flow cytofluorimetric analysis of drug accumulation by multi-drug resistant Trypanosoma brucei brucei and Trypanosoma brucei rhodesiense. Molecular and Biochemical Parasitology, 26:183-191. 
HERBERT, W.J. \& LUMSDEN, W.H.R. 1976. A rapid 'matching method' for estimation of hosts parasitemia. Experimental Parasitology, 40:427-431.

HIDE, G., TAIT, A., MAUDLIN, I. \& WELBURN, S.C. 1996. The origins, dynamics, and generation of Trypanosoma brucei rhodesiense epidemics in East Africa. Parasitology Today, 12:50-55.

HIDE, G., ANGUS, S.D., HOLMES, P.H., MAUDLIN, I. \& WELBURN, S.C. 1998. Trypanosoma brucei: Comparison of circulating strains in an endemic and epidemic area of sleeping sickness focus. Experimental Parasitology, 89:21-29.

KAMINSKY, R. \& ZWEYGARTH, E. 1989. Effects of in vitro cultivation in the stability of resistance to berenil, samorin, quinapyramine and melarsoprol in Trypanosoma brucei. Journal of Parasitology, 75:42-45.

KIBONA, S.N., MATEMBA, KABOYA, J.S. \& LUBEGA, G.W. 2006. Drug resistance of Trypanosoma brucei rhodesiense from Tanzania. Tropical Medicine and International Health, 11:144-155.

LEGROS, D., OLLIVIER, G., GASTELLU-ETCHEGORRY, M., PAQUET, C., BURRI, C., JANNIN, J. \& BÜSCHER, P. 2002. Treatment of human African trypanosomiasis: present situation and needs for research and development. Lancet Infectious Diseases, 2:437-440.

MATOVU, E., SEEBECK, T., ENYARU, J.C.K. \& KAMINSKY, R. 2001. Drug resistance in Trypanosoma bruceispp., the causative agents of sleeping sickness in man and Nagana in cattle. Microbes and Infection 3:763-770.

MATOVU, E., ITEN, M., ENYARU, J.C.K., SCHMID, C., LUBEGA, G.W., BRUN, R. \& KAMINSKY, R. 1997. Susceptibility of Trypanosoma brucei rhodesiense isolated from man and animal reservoirs to diminazene, isometamidium and melarsoprol. Tropical Medicine and International Health, 2:13-18.
MUTUGI, M.W., BOID, R. \& LUCKINS, A.G. 1996. Growth rates of suramin sensitive and resistant Trypanosoma evansi. Tropical Animal Health and Production, 28:147-150.

MUTUGI, M.W. 1993. Studies on suramin resistance in Kenyan stocks of T. evansi. Ph.D. thesis, University of Edinburgh.

NDUNG'U, J.M., MURILLA, G.A., MDIMINAZENECHI, R.M., MBWAMBO, H., SINYANGWE, L., MACHILA, N.H., DELESPAUX, V., GEERTS, S., BRANDT, J., PEREGRINE, A.S., McDERMOTT, J., HOLMES, P.H. \& EISLER, M.C. 1999. Area wide appraisal of drug resistance in trypanosomes infecting cattle in East and South Africa. Proceedings of ISCTRC, $25^{\text {th }}$ Meeting, Mombasa, Kenya. 27 September - 1 October 1999.

SCHONFELD, A., ROTTCHER, D. \& MOLOO, S.K. 1987. The sensitivity of trypanocidal drugs to Trypanosoma vivax isolated in Kenya and Somalia. Tropical Medicine and Parasitology, 38:177-180.

SCOTT, J.M. \& PEGRAM, R.G. 1974. A high incidence of Trypanosoma congolense strains resistant to homidium bromide in Ethiopia. Tropical Animal Health and Production, 6: 215-221.

VAN HOEVE, K. \& GRAINGE, E.B. 1965. Drug sensitivity of Trypanosoma brucei subgroup trypanosomes isolated from cattle in Alego. East Africa Trypanosomiasis Research Organisation Report for 1965.

WHO 2001. Recommendations of a scientific working group on sleeping sickness. World Health Organisation (WHO) report.

WHITESAND, E.F. 1960. Recent work in Kenya on control of drug resistant cattle trypanosomiasis. Proceedings of the $8^{\text {th }}$ ISCTRC Meeting, Jos, Nigeria: 141-154.

WRAGG, W.R., WASHBOURN, K., BROWN, K.N. \& HILL, J. 1958. Metamidium: a new trypanocidal drug. Nature, 182 : 1005-1006. 